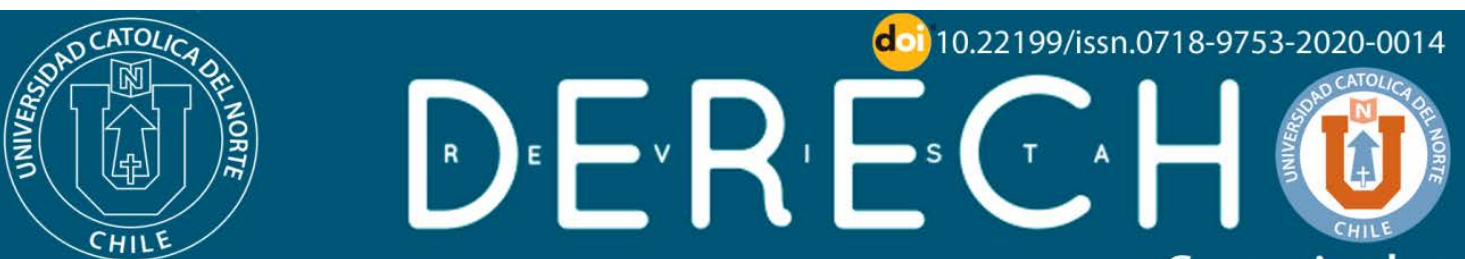

REVISTAS CIENTIFICAS

C o q u i m bo

ISSN: 0718-9753 (En línea)

\title{
Particularidades de la prescripción en los supuestos de abuso de las formas jurídicas y simulación en el Código Tri- butario chileno
}

\section{Special features in the limitation period for abuse of legal forms and sham cases in the chilean Tax Code}

\begin{abstract}
María Pilar Navarro Schiappacasse ${ }^{1}$ (D) https://orcid.org/0000-0001-7750-7617
'Universidad de O'Higgins, Rancagua, Chile. Instituto de Ciencias Sociales, Investigadora Postdoctoral. Abogada. Doctora en Derecho U. de Barcelona, España.
\end{abstract}

@mariapilar.navarro@uoh.cl

(cc) BY

\section{Resumen:}

Las normas generales antielusión chilenas buscan privar de efectos tributarios a aquellas planificaciones tributarias calificadas como abusivas o simuladas por un tribunal. Estas, presentan interesantes características en materia de prescripción, que las alejan de lo que hasta la fecha había sido la regla. En efecto, pese a que el abuso y la simulación están redactados en términos objetivos, el legislador parte de la base de que la actuación del contribuyente en estos casos es de mala fe, lo que genera el aumento del plazo de prescripción de la acción de fiscalización de tres a seis años por aplicación de las reglas de la prescripción extraordinaria. De otra parte, para que la Administración tributaria pueda fiscalizar los efectos emanado de este tipo de planificaciones tributarias, es necesario que los actos, contratos o negocios implementados por el contribuyente $y$ declarados elusivos hayan tenido lugar en períodos tributarios que resulten revisables por parte de la Administración tributaria.

Palabras Clave: Normas generales antielusión; Planificación tributaria; Economía de opción; Mala fe; Prescripción.

\begin{abstract}
:
The Chilean General Anti Avoidance Rules (GAARs) aim to deprive the fiscal effects resulting from a tax planning declared, by a tribunal, as abusive or as a sham. These institutions present some interesting characteristics in terms of the limitation period which distances them from what until now had been the absolute rule. In effect, even if the abuse and the sham are ruled in objective ways, the legislator considers the taxpayer's actions are performed in bad faith. The consequence is an increase of the limitation period from three to six years by the application of the extraordinary limitation period's rules. Additionally, in order for the Tax Administration to be able to inspect effects from this type of tax planning, it is necessary that the acts, contracts or legal business implemented by the taxpayer and declared elusive, have been taken place in revisable tax periods.

Keywords: General anti avoidance rule; Tax planning; Tax minimization; Bad faith; Limitation period.
\end{abstract}


Particularidades de la prescripción en los supuestos de abuso de las formas jurídicas...

\section{Introducción}

La Ley $\mathrm{N}^{\circ}$ 20.780, publicada en el Diario Oficial el 29 de septiembre de 2014, incorporó en el Código Tributario chileno las llamadas normas generales antielusión, que se encuentran vigentes desde el 30 de septiembre de 2015.

Un sector importante de la doctrina chilena, considera que la inspiración de esta normativa se encuentra en la regulación española; concretamente, en los artículos 15 y 16 de la Ley General Tributaria española (2003). Por todos, Ugalde Prieto (2018a, pp. 29, 40 y ss.). Ello explica que en este trabajo se haga referencia a la forma como han entendido los tribunales y la doctrina de dicho Estado estas figuras.

Tras la dictación de la Resolución Exenta del Servicio de Impuestos Internos $\mathrm{N}^{\circ}$ 68 y la Circular N 41, de 2016, ambas del 11 de julio de 2016, la Administración tributaria está habilitada para iniciar el procedimiento de calificación de actos o negocios como elusivos del artículo $4^{\circ}$ quinquies del Código Tributario (Decreto Ley $\mathrm{N}^{\circ} 830$, 1974) y requerir al Tribunal Tributario y Aduanero que declare que una determinada planificación tributaria es abusiva o simulada ${ }^{1}$. Cabe destacar, que en este punto la regulación se aparta de lo que ocurre a nivel comparado, toda vez que será un tribunal de justicia, y no el ente fiscalizador, el que determinará que concurren los presupuestos aplicativos del abuso de las formas jurídicas y de la simulación.

En este escenario, el examen que se propone efectuar busca determinar si las disposiciones que rigen la aplicación de las normas generales antielusión, establecen particularidades en materia de prescripción tributaria. Las hipótesis de este trabajo consisten, por una parte, en que en los supuestos de abuso de las formas jurídicas y de simulación, regulados en los artículos $4^{\circ}$ ter y $4^{\circ}$ quáter del Código Tributario (1974), el plazo de prescripción que se aplica es el extraordinario de seis años, debido a que el legislador ha entendido que en los casos de abuso y simulación el contribuyente se encuentra de mala fe. Por otra parte, se afirma que este lapso se cuenta desde que el contribuyente implementó el último de los actos que le permite obtener el ahorro tributario perseguido, sin importar para estos fines el hecho de que los efectos impositivos emanados de la planificación se hayan producido en períodos tributarios que aún son revisables por la autoridad administrativa.

\footnotetext{
${ }^{1}$ Con anterioridad a esta fecha, pese a que las normas generales antielusión se encontraban vigentes desde el 30 de septiembre de 2015, no podían ser utilizadas. Ello, por cuanto la Administración tributaria, al regular el procedimiento para la aplicación de estas normas mediante la Circular $\mathrm{N}^{\circ} 65$, de 23 de julio de 2015, incluyó la intervención obligatoria de un Comité Anti Elusión, el que no fue creado sino hasta la dictación de la Resolución Exenta del Servicio de Impuestos Internos $N^{\circ} 68$, de 11 de julio de 2016. Ahora bien, la Circular $\mathrm{N}^{\circ} 41$, de la misma fecha, derogó en esta parte a la Circular $\mathrm{N}^{\circ} 65$ antes indicada y limitó la intervención del citado Comité a los casos en que el Director estimase necesario contar con su parecer.
} 
Para demostrar estas hipótesis, el análisis se dividirá en tres partes. En la primera, se establecerá a qué tipo de planificaciones tributarias resultan aplicables las normas generales antielusión, identificando los deslindes entre la economía de opción, el abuso de las formas jurídicas y la simulación. En la segunda parte, se revisará el régimen jurídico de la prescripción de la acción de fiscalización del Servicio de Impuestos Internos en Chile, y los efectos que produce la afirmación del legislador de que en los casos de elusión el contribuyente no se encuentra de buena fe. En la tercera parte, se examinará si lo relevante a los fines de la prescripción, es que la Administración tributaria pueda examinar el período tributario en el que se terminó de implementar la planificación tributaria o aquel en el que se están produciendo los efectos jurídico-tributarios de los actos, contratos o negocios realizados. Para finalizar, se expresarán las conclusiones del análisis efectuado.

\section{La reacción del contribuyente frente al fenómeno impositivo}

\subsection{La planificación tributaria y su calificación como economía de opción, elusión o evasión}

Para iniciar el análisis propuesto, el punto de partida obligatorio es señalar que a la base del fenómeno impositivo se encuentra la noción de hecho gravado, según la cual una persona solo será sujeta a gravamen si su actuar verifica el presupuesto de hecho contemplado en una norma impositiva.

Frente a esta realidad, el contribuyente puede evitar tanto la configuración del hecho imponible como el conocimiento de la Administración tributaria de que ello aconteció. En este punto surge el concepto de planificación tributaria, que es la actividad desde la cual se genera toda la problemática asociada a la aplicación de normas generales antielusión.

La «planificación tributaria» es concebida por Ugalde Prieto y García Escobar (2010) como "...la facultad de elegir entre varias alternativas lícitas de organización de los negocios o actividades económicas del contribuyente, o incluso renunciar a la realización de negocios o actividades, todo con el fin de obtener un ahorro tributario" (p. 65). Con ciertas matizaciones, este concepto es seguido por la doctrina chilena ${ }^{2}$ y por la jurisprudencia de la Excma. Corte Suprema, así, y por ejemplo, en la sentencia del 27 de julio de 2015 "Pablo Andrés Gajardo Muñoz con Servicio de Impuestos Internos" (a propósito de la planificación tributaria que utilizó una sociedad acogida al régimen de 14 bis de la Ley sobre Impuesto a la Renta) y la sentencia de reemplazo del 14 de septiembre de 2015, "Comercial Key Limitada con Servicio de Impuestos Internos" (a propósito de los depósitos convenidos).

\footnotetext{
2 Vergara Hernández (2006, p. 12); Brzovic González (2003, pp. 360-361); Boetsch Gillet (2016, p. 96); Cattaneo Escobar y Burgos Arredondo (2017, p. 234); Matus Fuentes (2017).
}

Rev. derecho (Coquimbo, En línea) 2020, 27: e4467 
Particularidades de la prescripción en los supuestos de abuso de las formas jurídicas...

Ahora bien, se considera que la definición dada por los autores es muy restrictiva. En primer lugar, hace sinónimas dos figuras que son distintas y diferenciables como son la economía de opción y la planificación tributaria (Marín Benítez, 2013). De otra parte, su estrecha conceptualización impide incluir al abuso de las formas jurídicas y a la simulación. O si se quiere, más genéricamente, excluye a la elusión y a la evasión del concepto de planificación tributaria, porque la conceptualiza a partir de su licitud. En la doctrina chilena, Massone Parodi (2016, p. 566), incluye dentro del concepto de planificación fiscal no solo la obtención de ventajas fiscales admitidas por el sistema jurídico, sino también aquellas que desaprueba por ser elusivas.

Por ello se estima que debe preferirse un concepto más amplio de planificación fiscal, como comprensivo de la actividad destinada a obtener un ahorro impositivo (En esta misma línea la definición de Marín Benítez, 2013, p. 42, quien concibe la planificación tributaria como "un plan organizado para obtener el objetivo de menor pago de impuestos, sea su resultado lícito y legítimo, o no". También Osorio Morales y González Orrico, 2016, p. 20), porque la licitud o ilicitud no es un elemento de su esencia. Según el grado de mayor o menor respeto del ordenamiento jurídico (Alonso González, 2006, p. 3038), una concreta planificación tributaria podrá ser calificada de economía de opción ${ }^{3}$, elusión ${ }^{4}$ o evasión ${ }^{5}$. En la economía de opción y la elusión, lo buscado por el contribuyente será disminuir la cuantía de la obligación tributaria o evitar que esta surja; en la evasión, impedir que la autoridad sepa que se verificó el hecho imponible ${ }^{6}$.

Cabe indicar, que no es posible señalar a priori si una determinada planificación tributaria es lícita o ilícita, en el sentido de admitida por el sistema jurídico o no, porque dependerá de la regulación de cada Estado. Será de la primera clase si el ordenamiento jurídico acepta los efectos jurídico-tributarios emanados de ella; será del segundo tipo, en el caso contrario, ahora bien, esta ilicitud desde el punto de vista de la correcta determinación de la obligación tributaria no condiciona su ilicitud desde el punto de vista sancionatorio o penal. Como afirma Alonso Madrigal (2006), esta ilicitud es independiente de que adicionalmente "...pueda ser o no el presupuesto para la aplicación de sanciones de naturaleza punitiva en el ámbito tributario sancionador o en el ámbito penal" (p.164).

\footnotetext{
${ }^{3}$ Dicha figura está regulada en el inciso $2^{\circ}$ del artículo $4^{\circ}$ ter del Código Tributario (1974), el legislador chileno califica de «legítima» la «razonable opción» del contribuyente.

${ }^{4}$ Desde una perspectiva dogmática, uno de los mecanismos para luchar en contra de la elusión fiscal es incorporar en el ordenamiento jurídico una norma general antielusión. Tal carácter tiene el abuso de las formas jurídicas -y no la simulación-, regulado en los incisos $1^{\circ}$ y $3^{\circ}$ del artículo $4^{\circ}$ ter del Código Tributario (1974).

${ }^{5}$ El legislador chileno la establece la simulación en el artículo $4^{\circ}$ quáter del Código Tributario (1974), como una hipótesis de elusión, pese a que dogmáticamente corresponde a un caso de evasión.

${ }^{6}$ El artículo $4^{\circ}$ ter del Código Tributario (1974) considera simulación, para los efectos tributarios, el que determinados actos o negocios jurídicos disimulen la configuración del hecho gravado del impuesto $o$ la naturaleza de los elementos constitutivos de la obligación tributaria, o su verdadero monto o data de nacimiento.
} 
La economía de opción es un concepto novedoso en el acervo tributario chileno, y carecía de sentido antes de la inclusión de las normas generales antielusión, porque si una planificación fiscal no verificaba un determinado hecho gravado o captaba los presupuestos aplicativos de un beneficio tributario en sentido amplio, o no resultaba aplicable una norma particular antielusión, los efectos tributarios de ella debían ser respetados.

La doctrina señala que aún a falta de una norma específica antielusión, una planificación tributaria elusiva podría atacarse aludiendo a la vulneración de valores o principios superiores del ordenamiento, como el principio de capacidad contributiva o de igualdad (Carrasquer Clari, 2002, p. 134). Sin embargo, esta vía era absolutamente impensable en Chile, debido a la concepción del fenómeno tributario que se tiene, ligada a un respeto irrestricto del principio de legalidad, teniendo presente, además, la doctrina sentada por un fallo Corte Suprema, que declara

Que, así, el Servicio confunde, en este caso, dos conceptos jurídicos que tienen una diferencia notoria: el de evasión tributaria ?ilícito- [sic], con el de elusión, que consiste en evitar algo con astucia, lo que no tiene que ser necesariamente antijurídico, especialmente si la propia ley contempla y entrega las herramientas al contribuyente, como aquí ocurre, para pagar impuestos en una medida legítima a la que se optó, y no en aquella que se le liquida;. (Sociedad Inmobiliaria Bahía S. A. contra S.I.I., 2003, cons. 18)

La expresión "economía de opción", fue acuñada por Larraz López en su obra Metodología aplicativa del derecho tributario (1952), y corresponde a un ahorro tributario que se alcanza con pleno respeto a la legalidad tributaria. Existe una concordancia entre lo formalizado y la realidad, sin contrariar la letra de la ley ni su espíritu y sin que concurra mala fe en el contribuyente (Larraz López, 1952, pp. 61.62). Desde este punto de vista, el ahorro impositivo es inobjetable por el ente fiscalizador, distinto es que el Servicio de Impuesto Internos en la Circular No 65 (2015, p. 4), haya entendido que solo es admisible la economía de opción expresa, esto es, aquella que aparece contemplada de manera directa en la normativa tributaria. Legalmente, la economía de opción no está limitada a que la ley expresamente contemple la alternativa, ya que el Código Tributario prescribe que:

... no constituirá abuso la sola circunstancia que el mismo resultado económico o jurídico se pueda obtener con otro $u$ otros actos jurídicos que derivarían en una mayor carga tributaria; o que el acto jurídico escogido, o conjunto de ellos, no genere efecto tributario alguno, o bien los genere de manera reducida o diferida en el tiempo o en menor cuantía, siempre que estos efectos sean consecuencia de la ley tributaria. (Decreto Ley $\mathrm{N}^{\circ} 830$, art. 4 ter, inc. 2)

La elusión, por su parte, tradicionalmente se vincula con maniobras que buscan evitar la verificación del hecho gravado (Hensel, 2005, p. 230). Por tanto, no surge ni la obligación principal -consistente en enterar una suma de dinero en arcas fisca- 
Particularidades de la prescripción en los supuestos de abuso de las formas jurídicas...

les-, ni obligación accesoria alguna. A diferencia de lo que acontece en la economía de opción, en la elusión el resultado tributario se produce por una actuación del contribuyente que de manera artificiosa utiliza una estructura jurídica que no correspondía.

Finalmente, la evasión es una actuación del contribuyente que tiene lugar luego de que el hecho gravado se ha verificado, y que se caracteriza por el no pago de la obligación tributaria (Montecinos Araya, 2000, p. 161). Por ello, en este caso surgen tanto la obligación principal, como todas las accesorias impuestas por el ordenamiento jurídico para asegurar el cumplimiento de aquella.

El concepto de elusión en la legislación chilena presenta dos particularidades, que hacen necesario apuntar ciertas precisiones. De una parte, el abuso de las formas jurídicas -supuesto de elusión por excelencia-, incluye una hipótesis en las que el hecho imponible se verificó ${ }^{7}$. De otra parte, el legislador considera a la simulación del artículo $4^{\circ}$ quáter del Código Tributario (1974), como una especie del género elusión, en circunstancias que la simulación es un ejemplo clásico de evasión, toda vez que se realiza el hecho imponible, pero hay elementos que se ocultan ${ }^{8}$. La doctrina, ha hecho ver el error que presenta desde el punto de vista dogmático esta equiparación (Por todos, Yáñez Villanueva, 2014, p. 240) y la confusión que se ha generado es tal, que se ha llegado a señalar que esta regulación, si se la pone en relación con el ilícito del artículo 100 bis del Código Tributario, despenaliza tácitamente la simulación (Vergara Quezada, 2016).

En este punto, se considera que los principales problemas de esta asimilación se proyectan en el ámbito sancionatorio, pues es ahí donde cobra sentido la distinción entre evasión y elusión (Rozas Valdés y Anderson, 2007). Empleando una terminología propia del Derecho penal, desde el punto de vista del «desvalor de resultado», para el Fisco es indiferente que la falta de ingreso en arcas fiscales derive de una conducta en la que no se verificó el hecho imponible por una actuación artificiosa del contribuyente, o si ello tuvo lugar porque pese a que se realizó, el contribuyente lo ocultó. Lo que le interesará será que se determine correctamente la obligación tributaria y que se produzca el correspondiente pago, por lo demás, el legislador somete al abuso de las formas jurídicas y a la simulación a una regulación adjetiva similar, por lo que, en principio, el Servicio de Impuestos Internos no debiera preferir una sobre la otra. En efecto: i) la declaración es efectuada por un tribunal, previo requerimiento

\footnotetext{
${ }^{7} \mathrm{El}$ artículo $4^{\circ}$ ter del Código Tributario (1974) prescribe que uno de los supuestos en que existe abuso, es que se obtenga un resultado tributario concreto: que se disminuya la base imponible o la obligación tributaria.

${ }^{8}$ El texto original del proyecto de ley enviado por el Poder Ejecutivo al Congreso Nacional no contemplaba a la simulación como una especie del género elusión. Esta equiparación surgió con la indicación №367-362, del Vicepresidente de la República, de 9 de agosto de 2014, presentada tras la suscripción del Protocolo de acuerdo: "Por una reforma tributaria para un Chile más inclusivo" -en adelante Protocolo-, que se suscribió para destrabar la tramitación de la Ley № 20.780.
} 
del Director del Servicio de Impuestos Internos; ii) la cuantía mínima de la diferencia de impuestos esperada por el ente fiscalizador ha de exceder de 250 UTM; iii) el juez determinará la existencia de abuso o simulación estableciendo el monto de los impuestos, reajustes, intereses y multas que procedan y, iv) se contempla una infracción administrativa, vinculada a la intervención del asesor fiscal en la planificación o diseño de los actos o negocios declarados abusivos o simulados. Por el contrario, desde el punto de vista del castigo en sentido amplio, cobra importancia el «desvalor de acción», donde la diferenciación antes indicada sí es relevante. Por ello resulta criticable, desde el punto de vista del principio de proporcionalidad, que la figura del artículo 100 bis del Código Tributario (1975) imponga en abstracto una misma sanción al asesor tributario que diseñe o planifique un conjunto de actos o contratos -la ley incluye negocios-, que sean calificados por un tribunal como abusivos o simulados. Esta situación, solo puede ser solucionada por la interpretación que efectúen los órganos jurisdiccionales al momento de apreciar la cuantía de la sanción a imponer, que sea respetuosa de la diferencia entre una y otra figura.

De esta forma, pese al error dogmático apuntado, legalmente constituyen normas generales antielusión tanto el abuso como la simulación, con lo cual solo quedan fuera del ámbito de aplicación de estas cláusulas la economía de opción y los casos captados por una norma especial antielusión.

\subsection{El "abuso de las formas jurídicas" y la "simulación"}

\subsubsection{Diversas formas de luchar contra la elusión fiscal}

Cada ordenamiento jurídico, incorpora determinados mecanismos que buscan hacer frente a la elusión fiscal. Uno de ellos es la regulación positiva de normas generales antielusión, que corresponden a

...estructuras normativas cuyo presupuesto de hecho aparece formulado con mayor o menor grado de amplitud, y al cual se ligan unas consecuencias jurídicas, que, en suma, consistirán en la asignación a la Administración de unas potestades consistentes en desconocer el acto o negocio realizado con ánimo elusorio, para aplicar el régimen jurídico-fiscal que se ha tratado de eludir (García Novoa, 2003, p. 10; García Novoa, 2004, p. 259)

Los límites entre la elusión y la economía de opción son relativos para cada ordenamiento jurídico, y están determinados por la forma como se configura la norma general antielusión (Carrasquer Clari, 2002, pp. 146-147; Cipollina, 1992, p. 125), por lo que mientras más restrictivos sean sus presupuestos aplicativos, mayor será el ámbito de la economía de opción y menor el del abuso; a la inversa, mientras más restrictivo el espacio de la primera, mayor será el del segundo. 
Particularidades de la prescripción en los supuestos de abuso de las formas jurídicas...

El legislador mediante la Ley $N^{\circ} 20.780$ (2014), incorpora dos normas generales antielusión a la legislación tributaria chilena: el abuso de las formas jurídicas y la simulación. La tentación, es señalar que ambas figuras corresponden a nuevas facultades legales que se suman a aquellas con las que cuenta el Servicio de Impuestos Internos y que le permiten fiscalizar la declaración de impuestos efectuada por el contribuyente. Sin embargo, esta primera conclusión, apresurada, choca con la realidad chilena, en la que es un tribunal el que determina -luego de sustanciado el procedimiento regulado en el artículo 160 bis del Código Tributario-, que un acto jurídico es abusivo o simulado. La facultad de la Administración tributaria, en definitiva, consiste en poder instar a los tribunales para que establezcan que se está en presencia de actos elusivos.

Brevemente, se revisarán los presupuestos normativos de ellas, a fin de avanzar luego con el examen del plazo de prescripción aplicable en estos supuestos.

\subsubsection{El abuso de las formas jurídicas}

El abuso de las formas jurídicas está regulado en el Código Tributario:

Los hechos imponibles contenidos en las leyes tributarias no podrán ser eludidos mediante el abuso de las formas jurídicas. Se entenderá que existe abuso en materia tributaria cuando se evite total o parcialmente la realización del hecho gravado, o se disminuya la base imponible o la obligación tributaria, o se postergue o difiera el nacimiento de dicha obligación, mediante actos o negocios jurídicos que, individualmente considerados o en su conjunto, no produzcan resultados o efectos jurídicos o económicos relevantes para el contribuyente o un tercero, que sean distintos de los meramente tributarios a que se refiere este inciso(...)

En caso de abuso se exigirá la obligación tributaria que emana de los hechos imponibles establecidos en la ley. (Decreto Ley $N^{\circ} 830,1974$, art. $4^{\circ}$ ter)

Y contempla dos presupuestos aplicativos que copulativamente deben concurrir:

a) uno genérico, consistente en un determinado resultado: que se evite total o parcialmente la realización del hecho gravado (Hasta donde se tiene conocimiento, la doctrina no ha encontrado un caso en el que se dé el supuesto consistente en evitar parcialmente la realización de un hecho gravado. En este punto se sigue lo manifestado por Calvo Ortega, 2004, p. 59 y Calvo Vérgez, 2007 , p. 25 , para quienes es un error legislativo considerar que el hecho imponible puede verificarse parcialmente, toda vez que lo impide su carácter unitario), que se disminuya la base imponible o la obligación tributaria (en esta hipótesis el hecho imponible se verifica, pero el contribuyente capta el presupuesto de hecho de una exención o bonificación lato sensu o una rebaja improcedente. Báez Moreno, 2010, p. 470), o que se postergue o difiera el nacimiento de dicha obligación- el objetivo de las planificaciones tributarias 
muchas veces es diferir en el tiempo el nacimiento de la obligación tributaria. De ahí que Yáñez Villanueva (2014, p. 242), critique la inclusión de este supuesto, que no se contempla en la norma española que sirvió de base para la regulación del abuso de las formas jurídicas. También Avilés Hernández (2014, p. 247), quien considera que la norma es un atentado en contra del derecho de propiedad, la libertad económica y el principio de reserva de ley -, y

b) otro consistente en el análisis de la legítima razón de negocios o business purpose test, pues se debe examinar si los actos o negocios jurídicos, individualmente considerados o en su conjunto, producen o no efectos o resultados jurídicos o económicos "relevantes" -sea para el contribuyente o para un tercero-, distintos del mero ahorro tributario.

Si concurre el resultado tributario exigido por la norma y la planificación fiscal no supera el business purpose test, el efecto jurídico será que surge la obligación tributaria emanada de los hechos imponibles establecidos en la ley.

\subsubsection{La simulación: un supuesto de evasión equiparado a elusión}

La segunda norma general antielusión que contempla el Código Tributario chileno, es la simulación:

Habrá también elusión en los actos o negocios en los que exista simulación. En estos casos, los impuestos se aplicarán a los hechos efectivamente realizados por las partes, con independencia de los actos o negocios simulados. Se entenderá que existe simulación, para efectos tributarios, cuando los actos y negocios jurídicos de que se trate disimulen la configuración del hecho gravado del impuesto o la naturaleza de los elementos constitutivos de la obligación tributaria, o su verdadero monto o data de nacimiento. (Decreto Ley $N^{\circ} 830,1974$, art. 4 quáter)

La disposición, parte de la base de que el presupuesto de hecho contemplado en la norma impositiva se verificó.

Se ha definido a la simulación como "...la declaración de un contenido de voluntad no real, emitida conscientemente y de acuerdo entre las partes, para producir con fines de engaño la apariencia de un negocio jurídico que no existe o es distinto de aquel que realmente se ha llevado a cabo" (Ferrara, 1960, p. 56). De ahí que se distinga entre simulación absoluta, en la que tras el acto aparente nada hay, y simulación relativa, en la que tras el acto ostensible hay otro distinto que es el que realmente se ha llevado a cabo.

La regulación de la simulación dada por el Código Tributario claramente se refiere a la simulación relativa, porque la norma dispone que "... los impuestos se aplicarán a los hechos efectivamente realizados por las partes, con independencia de los actos o negocios simulados" (Decreto Ley N 830, 1974, art. 4 quáter), de lo que se co- 
Particularidades de la prescripción en los supuestos de abuso de las formas jurídicas...

lige que tras el acto aparente debe existir un acto efectivamente realizado, pero que permaneció oculto. De la misma postura es el Servicio de Impuestos Internos, el que en la Circular N $\mathrm{N}^{\circ} 65$ (2015, p. 15), instruyó que no es la simulación absoluta la regulada por el artículo $4^{\circ}$ quáter del Código Tributario.

\section{La obligación de declarar y el plazo de prescripción en los supues- tos de abuso o simulación}

La obligación tributaria surge al verificarse el presupuesto de hecho contemplado en una norma impositiva, el que debe ser demostrativo de capacidad contributiva (Sainz de Bujanda (1966, p. 551). Pese a que no existe una mención expresa a este principio en la Constitución chilena, la doctrina entiende que la misma se encuentra reconocida implícitamente las garantías constitucionales, específicamente en el principio de igualdad regulado en el artículo $19 \mathrm{~N}^{\circ} 20$ de la Constitución Política de la República, que asegura la igual repartición de los tributos (Salassa Boix, 2016, pp. 1018 y 1023). Así también lo ha entendido la jurisprudencia del Tribunal Constitucional chileno, que da cuenta de una progresiva evolución en la concepción de la capacidad económica hacia un principio jurídico implicado en la Constitución a través del principio de igualdad constitucional (Fernández Amor y Masbernat Muñoz, 2011, p. 584).

El sistema tributario chileno, en general, es de autodeterminación, por lo que, verificado el hecho gravado, se produce el nacimiento y devengo de la obligación tributaria y será, por regla general, el deudor de la relación impositiva o «contribuyente», quien deberá efectuar su cuantificación, declaración y pago en la oportunidad legalmente prevista para ello. Por su parte, el Fisco es el acreedor de la obligación fiscal, y está dotado legalmente de facultades exorbitantes que le permiten, dentro de los plazos de prescripción, establecer la correcta determinación de esa obligación tributaria liquidada por el contribuyente.

El Derecho tiene entre sus fines, otorgar certeza a los particulares en el desarrollo de su vida cotidiana, y la institución que posibilita el cumplimiento de lo anterior es la prescripción, ya que pone fin a las situaciones de incertidumbre jurídica, cumpliéndose ciertos requisitos, como apunta Alessandri Rodríguez, Somarriva Undurraga y Vodanovic Haklicka (2009, p. 153), imperativos vinculados a la seguridad impiden que las relaciones jurídicas se mantengan eternamente inciertas y que las situaciones de hecho se prolonguen, esto es, exige que se consoliden. De otra parte, estima que, si el acreedor no ejerce su derecho, no demuestra voluntad en conservarlo. Es así como el Código Civil (2000) define la prescripción como el "...modo de adquirir las cosas ajenas, o de extinguir las acciones y derechos ajenos, por haberse poseído las cosas o no haberse ejercido dichas acciones y derechos durante cierto lapso de tiempo, y concurriendo los demás requisitos legales" (art. 2492). 
El Código Tributario (1974) contiene una regulación particular de la prescripción. Así su artículo 200 distingue, según el lapso, entre prescripción «ordinaria», que es la regla general, y cuyo término es de tres años contados desde la expiración del plazo legal en que debió efectuarse el pago y la prescripción «extraordinaria», regulada su inciso $2^{\circ}$, que establece un plazo de carácter excepcional, de seis años, respecto de los impuestos sujetos a declaración -que son aquellos que deben ser pagados previa declaración del contribuyente o del responsable del impuesto-, cuando ella no se hubiere presentado o la presentada fuere maliciosamente falsa. La interpretación del Servicio de Impuestos Internos a estas disposiciones, se encuentra en la Circular $N^{\circ}$ 73, de 11 de octubre de 2001.

A continuación, el Código Tributario señala que la prescripción debe ser declarada de oficio por el tribunal con competencia tributaria, pues prescribe que "El Juez Tributario y Aduanero dispondrá en el fallo la anulación o eliminación de los rubros del acto reclamado que correspondan a revisiones efectuadas fuera de los plazos de prescripción" (Decreto Ley Nº 830, 1974, art. 146).

El régimen jurídico de la prescripción en materia tributaria se completa con la previsión legal de casos de suspensión, de interrupción, de aumento y de reanudación de este lapso.

\subsection{La mala fe del contribuyente en los supuestos de elusión}

Toda la configuración legal de las normas generales antielusión en Chile, se basa en que el abuso y la simulación están reñidas con la buena fe (Una vez cerrado el debate de la Ley $N^{\circ} 20.780$ en la Sala del Senado, cuando el proyecto de ley se encontraba en segundo trámite constitucional, el entonces Ministro de Hacienda manifestó que la reforma tributaria diseñó un sistema impositivo basado en dos principios: por un lado, se basa en la buena fe de los contribuyentes y, por otro, impide la elusión de acuerdo con las exigencias de la norma general antielusión, cuando el diferimiento de los tributos es simulado o abusivo, Historia de la Ley $\left.N^{\circ} 20.780,2014\right)$. En efecto, el Código Tributario establece un deber del Servicio de Impuesto Internos que consiste en "... reconocer los efectos que se desprendan de los actos o negocios jurídicos o de un conjunto o serie de ellos, según la forma en que estos se hayan celebrado por los contribuyentes" (Decreto Ley N 830, 1974, art. 4 bis, inc. 2). El inciso siguiente, prescribe que no hay buena fe si se eluden los hechos gravados, y ello acontece cuando se está en hipótesis de abuso o simulación.

Para Yáñez Villanueva (2014, pp. 238-239) la buena fe debió ser consagrada no como deber de la Administración, sino como una presunción de actuación del contribuyente. El proyecto de la Ley $\mathrm{N}^{\circ} 20.780$, no contempló originariamente ninguna mención a la buena fe. Su inclusión tuvo lugar tras la suscripción del Protocolo de Acuerdo (2014), y se introdujo mediante la indicación N³67-362, del Vicepresidente de la República, de 9 de agosto de 2014. 
Particularidades de la prescripción en los supuestos de abuso de las formas jurídicas...

Si no hay buena fe, es necesario entender a contrario sensu que el contribuyente se encuentra de mala fe, y la legislación tributaria contempla diversas consecuencias que toman en cuenta esta posición anímica. En contra Massone Parodi (2016, p. 623), para quien la elusión, por su propia naturaleza, no requiere de mala fe, y más bien es contraria a esta, porque la mala fe puede convertir la conducta o actuación en evasión y, eventualmente, en delito tributario.

Pese a que las normas generales antielusión han sido redactadas en términos objetivos -de ahí que no se siga a aquella doctrina que postula que el Servicio de Impuestos Internos tiene la carga procesal de destruir la presunción de buena fe del contribuyente. Al respecto, Ugalde Prieto (2018b, 77p.), porque se estima que lo que el ente fiscalizador debe hacer es acreditar que concurren los presupuestos aplicativos del abuso o de la simulación-, sin que haya ningún tipo de referencia a la prueba de alguna especial posición anímica, es innegable que hay una particular intencionalidad en el actuar del contribuyente. En esta línea, se sitúa parte de la doctrina tributaria y al Servicio de Impuestos Internos. Para Saffie (experto, asistente a la Comisión de Hacienda durante el estudio del proyecto), es irrelevante la consideración del elemento subjetivo, toda vez que el "...'abuso de las formas jurídicas' no requiere que se abuse maliciosamente de las normas sino que se actúe contra el propósito de las mismas" (Historia de la Ley N²0.899, 2016, p. 437). También Massone Parodi (2016, p. $556)$, para quien en sede tributaria -a diferencia de lo que acontece en las infracciones y sanciones- deben primar los hechos y resultados y no las intenciones y objetivos. El Servicio de Impuestos Internos en la Circular Nº5, de 2015, p. 2, expresamente recoge esta idea, pues instruye que la aplicación de abuso o simulación "...no depende de la existencia o prueba del dolo o malicia" (p. 2).

Ello es claro en la simulación, en la que hay una planificación tributaria que busca ocultar la verificación del hecho imponible o de elementos que sirvan para determinar la obligación tributaria. Pero también está presente en el abuso de las formas jurídicas.

Como afirma la doctrina española, en los casos de conflicto en la aplicación de la norma tributaria -símil al «abuso de las formas jurídicas» chileno- la actuación del contribuyente denota un propósito de eludir el impuesto. Incluso si la norma está redactada en términos objetivos, tal ánimo puede inducirse, precisamente, de los elementos objetivos que la cláusula general antielusión contempla (Palao Taboada (2009a, p. 172); Ruiz Almendral y Zornoza Pérez (2005, pp. 52-53). Es más, de la propia definición de norma general antielusiva, que en España no incluye a la simulación, consigna que la actuación del contribuyente es realizada con un especial «ánimo elusorio» (García Novoa, 2003, p. 10; García Novoa, 2004, p. 259).

En Chile, cierta doctrina ha hecho ver que es difícil concebir que el contribuyente aspire a un resultado más ventajoso sin que se haya propuesto dicho objetivo 
y haya realizado operaciones matemáticas para conseguirlo, representándose como cierta y aceptando la concatenación lógica de sus actos de resultado económico, por lo que habría que presumir tal intencionalidad (Gárate González, 2015, p. 202). A este respecto se estima que, en el caso del abuso, hay una elección de mala fe de una forma jurídica que no es la que correspondería y que solo se explica por la motivación del ahorro fiscal, y que está presente incluso si no hay una norma que expresamente así lo señale.

Tanto en el caso del abuso como de la simulación lo que pretende el contribuyente es rebajar la carga impositiva, pero la forma como logra ese resultado no es admitida por el ordenamiento tributario, y este reacciona.

Los artículos $4^{\circ}$ ter y $4^{\circ}$ quáter del Código Tributario (1974), no contemplan como presupuesto aplicativo de las figuras elusivas ningún tipo de elemento subjetivo. Se considera que ello no resultaba necesario, pues el sistema jurídico a priori en el artículo $4^{\circ}$ bis del mismo cuerpo legal ha efectuado una ponderación de la conducta del contribuyente y ha determinado que es reñida con la buena fe.

\subsection{La incidencia de la mala fe en el plazo de prescripción}

Se sostiene en este trabajo que la mala fe del contribuyente en los supuestos de elusión tiene una incidencia directa en materia de prescripción ${ }^{9}$. En efecto, se ha afirmado que cuando la planificación tributaria del contribuyente sea declarada abusiva o simulada, este se encontrará de mala fe. El artículo 200 del Código Tributario (1974), prescribe respecto de los impuestos sujetos a declaración que el plazo de prescripción puede aumentar de tres a seis años si el contribuyente no declara, o bien, la declaración es maliciosamente falsa.

La consideración relativa a la «malicia», es de orden subjetiva y es ponderada con carácter previo por el ordenamiento jurídico, toda vez que el Código Tributario expresamente señala que no hay buena fe en los supuestos de abuso de las formas jurídicas y simulación:

No hay buena fe si mediante dichos actos o negocios jurídicos o conjunto o serie de ellos, se eluden los hechos imponibles establecidos en las disposiciones legales tributarias correspondientes. Se entenderá que existe elusión de los hechos imponibles en los casos de abuso o simulación establecidos en los artículos $4^{\circ}$ ter y $4^{\circ}$ quáter, respectivamente. (Decreto Ley $\mathrm{N}^{\circ} 830,1974$, art. 4 bis, inc. 3)

En este contexto, la jurisprudencia de la Excma. Corte Suprema ha desligado esta exigencia de «malicia» del dolo penal y civil, y la vincula más bien con un dolo

\footnotetext{
${ }^{9}$ Obviamente, también la tendrá respecto de la aplicación del artículo 26 del Código Tributario. De ahí que se explique la regulación de una consulta popular en el artículo 26 bis del mismo texto legal. 
Particularidades de la prescripción en los supuestos de abuso de las formas jurídicas...

administrativo o tributario que debe ser acreditado por el Servicio de Impuestos Internos, el que consiste "...en la conciencia que tiene el contribuyente de que está adjuntando documentos no fidedignos o falsos, o que está ocultando antecedentes u operaciones con el objeto de disminuir sus impuestos..." (Doblevia Publicidad Limitada con Servicio de Impuestos Internos, 2015, cons. 6).

Si se examina la regulación de la simulación, se constata que el Código Tributario exige que se «disimule» la "...configuración del hecho gravado del impuesto o la naturaleza de los elementos constitutivos de la obligación tributaria, o su verdadero monto o data de nacimiento" (Decreto Ley N 830, 1974, art. 4 quáter). Según el Diccionario de la Lengua Española, "disimular», en una de sus acepciones, consiste en "Ocultar algo para que no se vea o para que parezca distinto de lo que es" (Real Academia Española, 2014, definición 4) y «falso» no es otra cosa que algo "fingido o simulado" (Real Academia Española, 2014, definición 1). Por tanto, una declaración simulada, que oculta alguno de los aspectos contemplados en el artículo $4^{\circ}$ quáter del Código Tributario (1974), antes referido no solo es falsa, al declarar algo que no existe, sino que además lo es de manera maliciosa, de forma tal que el plazo de prescripción aplicable es de seis años. Avilés Hernández (2014, p. 246), señala expresamente que la simulación presupone una posición subjetiva del contribuyente en orden a ocultar el negocio basal.

Si se centra ahora el examen en el abuso de las formas jurídicas, en uno de sus presupuestos aplicativos el hecho imponible no se verificó, por tanto, se podría afirmar que no ha de tener lugar la declaración, pues a falta de realización de la hipótesis normativa tampoco surge la obligación de declarar. Una opción para fundamentar la postura que se sostiene en este trabajo, a saber, que el plazo de prescripción en estos casos es de seis años, sería argumentar que en estos supuestos también hay engaño y ocultación. Sin embargo, esta es una postura minoritaria en la doctrina española (En España sostienen esta posición Palao Taboada 2009b, p. 23; López López y Báez Moreno 2004, pp. 133-134 y Alonso Madrigal, 2006) y en Alemania, si bien se acepta la presencia del engaño, ello es relevante para sancionar penalmente el abuso (Tiedemann, 2010, p. 275). Por lo demás, fundamentar de esta forma la ampliación del plazo, obligaría a considerar en cada caso si hubo o no ocultación o engaño.

La buena fe está vinculada a ciertos valores: honradez, corrección, rectitud, veracidad, confianza legítima, coherencia y racionabilidad (Boetsch Gillet, 2015, p. 38). A esto se debe agregar que la Excma. Corte Suprema ha manifestado que la prescripción extraordinaria tiene lugar cuando la declaración es no fidedigna. En el abuso de las formas jurídicas se produce una infracción del ordenamiento jurídico, de carácter indirecta, porque respetando la letra de la norma se vulnera su espíritu a través del empleo de formas jurídicas artificiosas cuya elección solo se explica por la motivación que precedió su elección, la que no es otra que la obtención de un determinado resultado tributario. Otra forma de entender esta institución, no se condi- 
ce con el hecho de que existe una reacción del sistema tributario que priva de efectos la planificación tributaria abusiva.

Al estar frente a una violación del ordenamiento jurídico tributario, mal se puede afirmar que es correcta la declaración del contribuyente, sino que más bien hay falsedad en lo declarado, porque el abuso actúa sobre la norma de cobertura reduciendo su extensión, y sobre la norma defraudada, esta última siempre de naturaleza tributaria, ampliando su ámbito de aplicación (adentrarse en la naturaleza jurídica de las normas generales antielusión requeriría de por sí un trabajo dedicado exclusivamente a este punto, por lo que para los efectos que se analizan baste señalar que se considera que este tipo de disposiciones constituyen una restricción teleológica. Para un examen de esta figura véase Larenz, 1980, pp. 385 y ss.).

En este sentido, se estima que existe un argumento adicional para considerar que la prescripción en los supuestos de aplicación de las normas generales antielusión es de seis años. Para ello, conviene examinar la regulación del ilícito del artículo 100 bis del Código Tributario (1974), que establece una infracción cuyo sujeto activo es una persona natural o jurídica que haya realizado la conducta sancionada que consiste en diseñar o planificar actos, contratos o negocios constitutivos de abuso o simulación, según lo dispuesto en los artículos $4^{\circ}$ ter, $4^{\circ}$ quáter, $4^{\circ}$ quinquies y 160 bis del Código Tributario (1974).

Lo cierto es que, a diferencia de lo que ocurre con el plazo general de prescripción de las infracciones establecido en el inciso $5^{\circ}$ del artículo 200 del texto en comento -que es de tres años contados desde la comisión de la infracción-, en este caso el lapso de prescripción es de seis años y se computa desde el vencimiento del término para declarar y pagar los impuestos eludidos, según lo dispuesto en el inciso $3^{\circ}$ del artículo 100 bis del Código Tributario (1974). Esta diferencia en la regulación que se mantuvo pese a las modificaciones que introdujo en esta última disposición la Ley $N^{\circ} 20.899$ (2016)-, no puede tener otra explicación que la de equiparar este plazo de prescripción con el que tiene el SIl para solicitar la declaración de abuso o simulación, por estas razones no se sigue en este punto a Boetsch Gillet (2016, p. 157), para quien la diferencia entre el plazo de prescripción aplicable a los artículos $4^{\circ}$ ter y $4^{\circ}$ quáter del Código Tributario - de tres años- y el que se establece para la infracción de seis-, deviene, a su juicio, en que la sanción administrativa prescribe anticipadamente, debido a que sin la declaración de elusión no se puede perseguir la sanción al asesor tributario de la planificación fiscal.

De esta forma, se estima que el sistema tributario prevé una hipótesis de prescripción extraordinaria, en los casos de impuestos sujetos a declaración, cuando la planificación tributaria del contribuyente sea declarada abusiva o simulada, toda vez que el legislador entiende que la declaración será maliciosamente falsa. Consecuentemente, el Servicio de Impuestos Internos podrá requerir al Tribunal Tributario 
y Aduanero la declaración de abuso o simulación dentro del término de seis años, contados desde la expiración del plazo legal en que debió efectuarse el pago del impuesto. Esto no supone una aplicación analógica de la elusión, sino un efecto legal que genera que la planificación tributaria realice los presupuestos aplicativos del abuso de las formas jurídicas o de la simulación. En contra de lo anterior, se encuentra Boetsch Gillet (2016), para quien la buena fe debe reconocerse, la elusión es una situación excepcional y en cuanto tal, el intérprete debe darle "una aplicación restrictiva y jamás susceptible de aplicación por analogía" (p. 90), pues estima que hay una diferencia sustancial entre una declaración maliciosamente falsa y la mala fe.

\section{Actos jurídicos realizados o concluidos en ejercicios prescritos: su incidencia en la aplicación de la norma general antielusión}

Puede ocurrir, y será muy probable que ocurra, que el o los actos jurídicos que conformen la planificación elusiva hayan tenido lugar en períodos tributarios que se encuentran prescritos -más allá de los seis años antes indicados-, pero cuyas consecuencias jurídicas continúan produciéndose en ejercicios que pueden ser objeto de revisión por el Servicio de Impuestos Internos. En este sentido es necesario precisar qué se toma en cuenta, para determinar si la acción de fiscalización está prescrita: si el período en el que se ejecutaron los actos jurídicos que originan la elusión o aquel en el que se producen los efectos jurídicos emanados de estos.

Hasta donde se tiene conocimiento, el tema no ha sido tratado por la doctrina chilena (a excepción de una breve mención por parte de Walker Mena, 2017, p. 150). Por ello, puede ser de ayuda examinar la experiencia española, ya que ahí este tipo de problemas se ha presentado a propósito del fraude a la ley regulado en la Ley 230/1963 (art. 24), y existen pronunciamientos judiciales firmes.

El fraude a la ley tributaria era la norma general antielusiva regulada en la Ley 230/1963, General Tributaria, de 28 de diciembre. La Ley 58/2003, de 17 de diciembre, nueva Ley General Tributaria, derogó el texto normativo que contenía el fraude a la ley tributaria e incorporó una nueva cláusula general antielusión. Los presupuestos aplicativos de ambas figuras difieren; sin embargo, esta situación no influye en el examen que se analizará a continuación, el que pretende revisar la interpretación que ha efectuado la jurisprudencia respecto de la problemática de la prescripción de la acción de fiscalización de la Administración tributaria, en los casos en que se pretende aplicar una cláusula antielusiva de carácter general.

\subsection{La experiencia española: una mirada a la jurisprudencia del tribunal supremo}

Es posible identificar dos etapas en la jurisprudencia del Tribunal Supremo español, símil a la Corte Suprema chilena en esta materia. En un primer momento, 
dicho órgano jurisdiccional consideró que no podía declararse el fraude a la ley tributaria respecto de negocios jurídicos realizados en un período prescrito -por hechos no sobrevenidos, sino presentes en el ejercicio respectivo-, cuando estos no fueron objeto de comprobación por la Administración tributaria.

Tal razonamiento se basó en que esta figura debía ser calificada en relación con hechos, actos o negocios jurídicos celebrados, sin que fuese jurídicamente admisible proyectarlo solo respecto de los efectos jurídicos y económicos derivados del cumplimiento de tales actos o negocios, si estos quedaban fuera de la posibilidad de una declaración en tal sentido por razones temporales. Ello, a juicio del tribunal, obligaba lógicamente a asociar la declaración de fraude a la ley con períodos tributarios concretos en los que se celebraron los hechos, actos o negocios específicos aquejados de fraude, pues de otro modo "... siempre quedaría abierta la posibilidad, en favor de la Inspección, de declarar el fraude de ley en relación con ejercicios en que se mantuvieran efectos ventajosos derivados de actos u operaciones en principio aceptadas" (Recurso $N^{\circ} 581 / 2013,2014$, fundamento de derecho 4, n. 3). Se debe señalar que previamente la Administración había comprobado la planificación tributaria sin encontrar irregularidades, por lo que además la sentencia analiza la teoría de los actos propios. La tesis del Abogado de Estado fue que esta facultad de declarar el fraude a la ley -que en España es de competencia de la Administración tributaria-, no prescribía y se extendía a cualquier período impositivo, la que además incluía la valoración de los negocios concertados en el período prescrito como si fueran objeto de inspección, toda vez que producían efectos en ejercicios revisables. Para una crítica de esta jurisprudencia, véase Palao Taboada (2014, pp. 41 y ss.).

Sentada esta jurisprudencia y siendo conocida por el Tribunal EconómicoAdministrativo Central español, en su resolución de 11 de septiembre de 2014 (05852/2011), este resolvió en un caso similar en contra del criterio del Tribunal Supremo español y señaló que era factible declarar el fraude a la ley en estos supuestos. Fundamentó su decisión en que el criterio expuesto del máximo tribunal no correspondía a una posición consolidada, sino solo una sentencia aislada y, por lo demás, esgrimió motivos de congruencia, ya que a esa fecha existían otras sentencias de la Audiencia Nacional que se referían a casos similares, que habían sido recurridas de casación por la Administración. Así, consideró que en el momento en que acaecieron las actuaciones del contribuyente, el ente fiscalizador carecía de elementos para iniciar sin más un procedimiento para decretar que se estaba en presencia de la figura del artículo 24 de la Ley 230/1963, porque lo impedía tanto el hecho de que en estos casos se impugnaba el resultado que en conjunto producían las operaciones, cuanto en atención a que determinar la existencia del fraude a la ley era un análisis que debía realizarse caso a caso (Fundamentos de derecho $2^{\circ}$ y $3^{\circ}$, de la Resolución 05852/2011 del Tribunal Económico Administrativo Central Español. Para una crítica a esta decisión, véase Bas Soria (2014, pp. 151-152). 
Particularidades de la prescripción en los supuestos de abuso de las formas jurídicas...

La segunda etapa en la jurisprudencia del Tribunal Supremo español da cuenta del cambio de criterio expreso en esta materia, ya que declaró superada la postura mantenida previamente a través de la sentencia de 4 de julio de 2014. En efecto, la nueva línea jurisprudencial se inicia con la sentencia de 5 de febrero de 2015 (Fundamento 3 de derecho del Recurso $N^{\circ}$ 4075/2013), que declara que dentro de las actuaciones de comprobación se pueden verificar operaciones cuyo origen se encuentra en ejercicios fiscales prescritos, cuando los efectos de tales actos o negocios se sigan produciendo. Tal proceder lo justifica a fin de evitar la imposibilidad de actuar frente a la ilegalidad, ya que sostener el criterio primitivo equivaldría a consagrar un principio de "igualdad fuera de la ley", "igualdad en la ilegalidad" o "igualdad contra ley" en materia tributaria (Recurso N ${ }^{\circ}$ 4072/2013, fundamento de derecho 6; Recurso $N^{\circ} 682 / 2014$, fundamento de derecho 2). Ahora bien, cabe señalar que el Tribunal Supremo español ha hecho una precisión en su doctrina. Si bien mantiene la línea jurisprudencial anotada, expresa que el fraude de ley "se aplicará, claro está, con respecto a los impuestos y ejercicios no prescritos, sin que esta obvia exigencia haya de incorporarse al correspondiente acuerdo de declaración" (Recurso № 2218/2015, Fundamento de derecho 6, b; Para una crítica a esta línea jurisprudencial, véase Álvarez Barbeito, 2015, pp. 183 y ss.).

\subsection{La solución al problema en chile: una revisión a la jurisprudencia vi- gente y al artículo octavo transitorio de la Ley $\mathbf{N}^{\circ} \mathbf{2 0 . 8 9 9}$}

El máximo tribunal chileno, a propósito de la revisión de una pérdida de arrastre en el impuesto de primera categoría -que a juicio del contribuyente se encontraba prescrita-, manifestó que su doctrina asentada era que:

...tratándose de la determinación de un impuesto actual en que el contribuyente hace valer pérdidas de arrastre provenientes de ejercicios anteriores al amparo del artículo 31 de la Ley de Impuesto a la Renta, no procede que el Servicio de Impuestos Internos, al exigir que se acrediten fehacientemente tales pérdidas, ejerza sus facultades fiscalizadoras para revisar impuestos prescritos, sino que sólo puede controlar que los gastos que se hacen valer respecto de la determinación de un impuesto actual se encuentren justificados. (Sociedad Comercial y de Inversiones Ltda. con Servicio de Impuestos Internos, 2015, cons. 4; Comercial Constructora Lomas Limitada con Servicio de Impuestos Internos VIII de Concepción, 2017, cons. 4).

Ello, a su juicio, resulta de toda lógica, ya que, al imputar las pérdidas a utilidades de un período tributario, el Servicio de Impuestos Internos podrá revisarlas desde el momento de su generación, sin que proceda oponer prescripción, pues de otro modo el contribuyente podría determinar su propio plazo de prescripción. Así, el máximo tribunal concluye que:

...queda claro que la jurisprudencia asentada de esta Corte en materia de pérdida de arrastre permite la revisión de operaciones que exceden el período 
de prescripción siempre que incidan en tributos actuales, por lo que no resulta procedente rever el conflicto jurídico, sobradamente resuelto (Sociedad Comercial y de Inversiones Ltda. con Servicio de Impuestos Internos, 2015, cons. 4; Comercial Constructora Lomas Limitada con Servicio de Impuestos Internos VIII de Concepción, 2017, cons. 4)

La jurisprudencia asentada por la Excma. Corte Suprema parece ser clara, y aplicada a los supuestos de abuso o simulación permitiría entender que pese a que los actos, contratos o negocios -individualmente considerados o en su conjunto- hayan tenido lugar en un ejercicio prescrito, el Servicio de Impuestos Internos puede objetar los efectos que se produzcan en períodos en que pueda ejercer las facultades de fiscalización.

Sin embargo, surge la duda acerca de si la regulación de la Ley $\mathrm{N}^{\circ} 20.780$ (2014), complementada por la Ley $N^{\circ} 20.899$ (2016), introduce algún elemento normativo adicional, que permita variar la postura consolidada del máximo tribunal chileno en esta particular materia.

La respuesta a esta interrogante, se debe buscar en los artículos que determinan la vigencia temporal de las medidas generales antielusión, esto es, los que precisan el momento desde el que se aplican las citadas normas, materia regulada por las disposiciones transitorias: el inciso segundo de la decimoquinta transitoria de la Ley $\mathrm{N}^{\circ} 20.780$ (2014) y octava transitoria de la Ley N² 20.899 (2016).

Las normas transitorias antes indicadas, han sido interpretadas por el Servicio de Impuestos Internos ${ }^{10}$. Según dicha institución, en el caso de la disposición decimoquinta transitoria de la Ley $N^{\circ} 20.780$ (2014), lo determinante no era la fecha de ejecución o celebración de los hechos, actos o negocios o conjunto o serie de ellos antes de la entrada en vigencia de las normas generales antielusión de Código Tributario, sino el hecho de que al momento de entrada en vigor de tales cláusulas se encontrara "...pendiente el cumplimiento de sus efectos jurídicos o tributarios..." (Circular $\mathrm{N}^{\circ} 55,2015, \mathrm{n} .8$ ). Así, lo que se debía analizar para aplicar estas figuras, era que las consecuencias jurídicas se continuasen produciendo al 30 de septiembre de 2015. De esta forma, independientemente de la fecha en que tuvieron lugar hechos, actos o negocios por parte del contribuyente, en tanto los efectos de estos se siguieran produciendo, el Servicio de Impuestos Internos podía fiscalizar.

La interpretación del Servicio de Impuestos Internos se basaba en el hecho de que la disposición transitoria en comento, aludía a que lo prescrito en las normas que contienen las medidas generales antielusión "... sólo será aplicable respecto de los hechos, actos o negocios, o conjunto o serie de ellos, a que se refieren dichas disposiciones,

\footnotetext{
${ }^{10}$ La disposición decimoquinta transitoria de la Ley $\mathrm{N}^{\circ} 20.780$, mediante la Circular $\mathrm{N}^{\circ} 55,16$ de octubre de 2015, y la disposición octava transitoria de la Ley $\mathrm{N}^{\circ} 20.899$, a través de la Circular $\mathrm{N}^{\circ} 42$, de 11 de julio de 2016.
} 
Particularidades de la prescripción en los supuestos de abuso de las formas jurídicas...

realizados o concluidos a partir de la entrada en vigencia de las mismas" (Ley N²0.780, 2014, art. 15 transitorio). Del análisis de la disposición transcrita, la Administración tributaria concluía que no era posible entender que el legislador había utilizado como sinónimas "... de la expresión 'realizados y concluidos'” (Circular № 55, 2015, p. 2), por lo que les atribuía un significado diverso.

Este criterio era claramente trasladable a la prescripción de la acción de fiscalización, y por lo demás, se encontraba en la línea con la jurisprudencia de los tribunales, pero no respetaba el texto del Protocolo de Acuerdo (2014) que si bien es cierto no constituye un elemento de interpretación histórica de la ley, al no haber tenido lugar en el Congreso Nacional, fue el acuerdo que se alcanzó, y que permitió la aprobación de la Ley $N^{\circ} 20.780$ (2014). El Protocolo expresamente declaraba que "La norma general anti-elusión/anti-simulación sólo aplicará para actos, contratos, transacciones futuras, esto es, ocurridos a partir de la entrada en vigencia de la norma" (Por una reforma tributaria para un Chile más inclusivo, 2014, punto 6)

La ambigüedad de las expresiones "realizados" o "concluidos" fue hecha notar por la doctrina, la que consideró que era necesario esperar la interpretación que efectuara la Administración tributaria (Blanche Reyes, 2014, p. 11). La que realizó el SII causó tanto ruido, que fue necesaria una precisión por parte de la Ley $\mathrm{N}^{\circ} 20.899$ (2016), casi seis meses después de la fijación de este criterio por el ente fiscalizador. El origen de esta norma se encontraría, para Ugalde Prieto (2018a, p. 286), en las numerosas y fundadas críticas que se realizaron tanto al inciso $2^{\circ}$ del artículo decimoquinto transitorio de la Ley $\mathrm{N}^{\circ} 20.780$ (214), y la interpretación de la norma efectuada por el Servicios de Impuesto Internos, mediante la Circular N 55 (2015).

En efecto, la disposición transitoria octava de la Ley Nº 20.899 (2016), contiene una interpretación auténtica de lo prescrito en la norma transitoria decimoquinta de la Ley $N^{\circ} 20.780$ (2014), y cambia completamente el criterio (De hecho, cuando la Ley $\mathrm{N}^{\circ}$ 20.899, se encontraba en primer trámite constitucional en la Cámara de Diputados, el Director del Servicio de Impuestos Internos manifestó expresamente que "La norma propuesta no es retroactiva, pues en ningún caso ella se aplica ni se ha interpretado que aplique a operaciones o resultados ocurridos antes del 30/09/2015". Historia de la Ley $\mathrm{N}^{\circ} 20.899,2016$, p. 192), pues ahora lo determinante no será que los efectos se sigan produciendo con la entrada en vigencia de esta regulación que contiene las medidas generales antielusión, ni tampoco la fecha en la que estos se comiencen a generar, sino que lo relevante para precisar el ámbito temporal de aplicación de esta legislación será el momento en que se hayan estipulado las “...características o elementos que determinan sus consecuencias jurídicas para la legislación tributaria..." (Ley N² 20.899, 2016, art. 8 transitorio), de los hechos, actos, contratos, o serie o conjunto de ellos ${ }^{11}$. Aquí el legislador pone el énfasis en la fecha

\footnotetext{
${ }^{11}$ La norma distingue el momento en el que fueron fijadas las características o elementos esenciales de los hechos, actos o negocios, o conjunto o serie de ellos. Si esto ocurrió antes del 30 de septiembre 
de celebración de estos hechos y actos jurídicos, si esa es la oportunidad en la que se fijan las características apuntadas, para determinar si en ese momento se encontraban vigentes las medidas generales antielusión y, consecuentemente, si los efectos que se producen se encuentran comprendidos en las hipótesis normativas que estas contienen.

Sentado que al legislador lo que le interesa es que se controlen los actos jurídicos que generan efectos tributarios, y no los efectos por separado, la pregunta que sigue es: ¿tiene esto alguna incidencia cuando los hechos, actos o negocios o conjunto o serie de ellos se han llevado a cabo en períodos prescritos -pero realizados o concluidos una vez vigentes las normas generales antielusión-, si los efectos jurídicos o tributarios continúan produciéndose en ejercicios que pueden ser objeto de comprobación?

Es claro que el legislador opta porque sea el momento de la realización o conclusión de tales hechos, actos, negocios, o conjunto o serie de ellos el que determine el ámbito de aplicación temporal de las normas, y esto tiene incidencia en el cómputo del plazo de prescripción.

Dicha conclusión, se ve reforzada si se toma en cuenta el texto expreso del inciso final del artículo $4^{\circ}$ quinquies del Código Tributario (1974), que alude a que lo que se declara abusivo o simulado son determinados actos jurídicos, y no los efectos derivados de estos, por lo que estos debieran haber tenido lugar en un período tributario que aún sea revisable por el Servicio de Impuestos Internos. El Código Tributario, en la parte pertinente, prescribe que:

En caso que se establezca la existencia de abuso o simulación para fines tributarios, el Tribunal Tributario y Aduanero deberá así declararlo en la resolución que dicte al efecto, dejando en ella constancia de los actos jurídicos abusivos o simulados, de los antecedentes de hecho y de derecho en que funda dicha calificación, determinando en la misma resolución el monto del impuesto que resulte adeudado, con los respectivos reajustes, intereses penales y multas, ordenando al Servicio emitir la liquidación, giro o resolución que corresponda... (Decreto Ley N 830, 1974, art. 4 quinquies, inc. 6)

Por lo demás, la jurisprudencia de los propios tribunales de justicia permite avalar esta interpretación, ya que el Tercer Tribunal Tributario y Aduanero de la Re-

de 2015, los actos jurídicos y hechos no se verán alcanzados por las disposiciones de las normas generales antielusión y sus normas complementarias. En cambio, si dichas características o elementos esenciales se fijaron con posterioridad a tal fecha, serán revisables conforme a esta nueva normativa, lo que también acontecerá si los hechos, actos, negocios o conjunto o serie de ellos fueron realizados o concluidos con anterioridad al 30 de septiembre de 2015, pero que a contar de esta fecha hayan sido modificados sus características o elementos esenciales. En este último caso, el Servicio de Impuestos Internos podrá fiscalizar solo estas consecuencias posteriores surgidas a partir de la modificación. 
Particularidades de la prescripción en los supuestos de abuso de las formas jurídicas...

gión Metropolitana, conociendo de un caso en que el Servicio de Impuestos Interno tasó según el artículo 64 del Código Tributario (1974) el valor de una operación realizada en un período prescrito, manifestó:

Que todo lo expuesto solo permite concluir a esta sentenciadora que tratándose de la determinación de un impuesto actual en que el contribuyente invoca un gasto, haciendo valer pérdidas de arrastre provenientes de ejercicios anteriores al amparo del artículo 31 de la Ley de Impuesto a la Renta, no procede que el Servicio de Impuestos Internos, al exigir que se acrediten fehacientemente tales pérdidas, ejerza la facultad de tasación contemplada en el Artículo 64 inciso tercero del Código Tributario, para modificar los resultados de operaciones acaecidas fuera de los plazos de prescripción, sino que sólo puede controlar que los gastos que se hacen valer respecto de la determinación de un impuesto actual se encuentren justificados y cumplan con los requisitos que la citada norma legal contempla... (Inmobiliaria Las Palmas de Maipú Dos S.A. con XV Dirección Regional Santiago Oriente del SII, 2016, cons 7) ${ }^{12}$

De lo expuesto, se estima que para el legislador la fecha que ha de tomarse en cuenta para efectos de la prescripción es aquella que corresponde al último de los actos, contratos o negocios ejecutado -siempre que sus características o elementos que determinan las consecuencias jurídicas tributarias no sean alteradas en el futuro- que permita obtener el ahorro tributario buscado, porque en ese momento la planificación tributaria queda implementada y permite obtener potencialmente tal ahorro.

Si bien es cierto que, desde un punto de vista epistemológico, es innegable que la operación realizada en abuso no puede ser valorada sino hasta que despliega sus efectos (Bas Soria, 2014, p. 151), el contexto normativo de las cláusulas generales antielusión es diverso y presenta particularidades en lo que respecta al elemento que debe tomarse en cuenta para determinar si se puede declarar el abuso de las formas jurídicas o la simulación.

\subsection{Aplicación a un caso práctico}

Se ha señalado que el plazo de prescripción de la acción de fiscalización es de seis años en los supuestos de abuso de las formas jurídicas y simulación, el que comienza a correr cuando se implementa el último de los actos, contratos o negocios que integran la planificación tributaria.

Los efectos tributarios de lo que se sostiene en este trabajo, pueden quedar más claros si se aplican al emblemático caso de planificación tributaria Coca Cola

\footnotetext{
${ }^{12}$ Sin que el pronunciamiento fuese posteriormente objeto de recurso de casación, seguramente, para evitar las implicancias que se generarían si tal criterio fuese sustentado por nuestro máximo tribunal.
} 
Embonor S.A. con SII, conocido por la justicia tributaria en Chile ${ }^{13}$, alterando el contexto normativo y temporal en que se implementó la planificación. Así, se propone examinar la planificación considerando que a la fecha en que ocurrieron estos hechos, las medidas generales antielusivas se encontraban vigentes y resultaban aplicables.

La fiscalización del Servicio de Impuestos Internos se inicia cuando Coca Cola Embonor S.A., en su declaración de impuesto anual a la renta del año tributario 2010, consigna una pérdida afecta al régimen general del impuesto de primera categoría de la Ley sobre Impuesto a la Renta (1974), solicitando una devolución resultante de la diferencia entre el pago provisional por utilidades absorbidas y los créditos por gastos en capacitación, menos el monto relativo al impuesto único inciso $3^{\circ}$ artículo 21 de la Ley sobre Impuesto a la Renta (1974).

El ente fiscalizador objeta el resultado tributario de la agencia en Islas Caimán de Coca Cola Embonor S.A. y la pérdida de arrastre utilizada como gasto por el contribuyente, en la parte correspondiente a pérdidas generadas por tal agencia, pues dichos gastos no se acreditaron en la fase administrativa. En definitiva, mediante resolución el Servicio de Impuestos Internos rechazó parte de la devolución de impuestos solicitada y rebajó la pérdida de arrastre.

La planificación tributaria implementada por el contribuyente consta de los siguientes pasos:

i) con fecha 25 de marzo de 1999, constituye Agencia en Islas Caimán y con esa misma data la Agencia emite bonos con vencimiento en 7 años;

ii) con fecha 14 de abril de 1999, Coca Cola Embonor S.A. constituye una filial en las Islas Caimán, con un supuesto capital equivalente al monto del préstamo previamente contratado;

iii) con fecha 20 de mayo de 1999 la filial en Islas Caimán, Embotelladora Arica Overseas, adquiere la totalidad de las operaciones de embotellado de Inchcape Pie representada en Latinoamérica por la sociedad ILABSA y en Chile por Inchcape Bottling Chile S.A. La operación se habría materializado mediante la compra por parte de dicha filial de la totalidad de las acciones de Inchcape Bottling Chile S.A. de propiedad de ILABSA;

iv) el 14 de diciembre de 1999, la sociedad filial en Chile de Coca Cola Embonor S.A., llamada Embonor S.A., celebra un contrato de compraventa de las 4.338.766 acciones que la sociedad filial Arica Overseas mantenía en Inchcape Bottling Chile S.A. El monto de la transacción se efectúa a valor libro;

\footnotetext{
${ }^{13}$ En Sentencias del caso en el Tribunal Tributario y Aduanero de la Región Arica y Parinacota del 2 de abril 2012; Corte de Apelaciones de Arica del 6 de junio de 2012, y de la Corte Suprema. 23 de julio de 2013.
} 
Particularidades de la prescripción en los supuestos de abuso de las formas jurídicas...

v) en diciembre del 2002, la agencia en Islas Caimán habría contratado un nuevo préstamo. Lo mismo volvió a realizar en el año 2004, cuyos términos fueron modificados en el año 2006;

vi) en el 2005, Embonor S.A., filial en Chile, dueña de Embotelladora WiIliamson S.A. se dividió en dos sociedades, Embonor S.A. como continuadora legal, radicándose en ella las actividades de transporte, y Nueva Embonor S.A. como sociedad que nace con los activos correspondientes al área de producción, embotellado y comercialización de las plantas WiIliamson Balfour S.A;

vii) luego de la división, la matriz Coca Cola Embonor S.A. absorbe a Nueva Embonor S.A., disolviéndose esta última, como consecuencia de la compra del $100 \%$ de sus acciones. Dada la fusión, se habría producido una cuenta por cobrar entre Coca Cola Embonor S.A. y su relacionada Embotelladora Arica Overseas, mediante la cual la primera le adeudaría los valores de las transacciones de compraventa a dicha empresa situada en Islas Caimán. Por esta razón, a través de la Agencia, Coca Cola Embonor S.A. sería deudora y a su vez, propietaria de Embotelladora Arica Overseas S.A., y

viii) en el año comercial 2007, la Agencia en Islas Caimán, suscribe contratos de créditos bilaterales con bancos y realiza prepagos parciales al crédito sindicado con el financiamiento obtenido por dichos créditos y dinero obtenido por la colocación de la Serie A de bonos emitidos por Coca Cola Embonor S.A (Coca Cola Embonor S.A. con SII, 2012).

Es cierto que el caso se resolvió -en primera instancia- por una interpretación que estimó que los gastos no eran necesarios para producir la renta, y no hubo una consideración especial a la naturaleza elusiva de la planificación más que en obiter dicta (Acertadamente; Vergara Quezada, 2015, p. 225), en que se declaró que la planificación tributaria carecía de una «legítima razón de negocios».

Sin embargo, perfectamente esta planificación podría haber sido cuestionada empleando las normas generales antielusión, más aún si se tiene presente que existían pronunciamientos del Servicio de Impuestos Internos que avalaba la operatoria negocial desplegada (La defensa señaló que el contribuyente de buena fe se había acogido a los criterios expresados por el Servicio de Impuestos Internos en interpretaciones de las disposiciones tributarias -concretamente, a lo instruido en los Oficios 5.077, de 1978 y 3.424, de 2006- que permitían la deducibilidad de gastos por intereses en la medida que la inversión tuviese la potencialidad de generar rentas gravadas con impuesto a sobre la renta), que la planificación se recoge en el Caso 8 del Catálogo de Esquemas Tributarios del SII de 2018 (Servicio de Impuesto Internos, 2019, pp. 19-20), y que el reclamante invocó la aplicación del artículo 26 del Código Tributario (1974), se reitera aquí que la consideración de que en los casos de abuso de las formas jurídicas y simulación el contribuyente se encuentra de mala fe. Por ello, se estima que mal podría haberse acogido a lo dispuesto en el artículo 26 del Código Tribu- 
tario (1974), y ampararse en una interpretación del Director de las disposiciones tributarias.

El contribuyente contrató una serie de préstamos para financiar la constitución de una filial en Islas Caimán, paraíso tributario, la que a su vez estableció ahí una agencia. Los desembolsos derivados de los intereses pagados para financiar tal adquisición fueron tan elevados, que se incorporaron en el resultado tributario anual del contribuyente como pérdida de arrastre, además de constituir un gasto del año tributario respectivo. Si se fija la última de las operaciones efectuadas por el contribuyente para financiar las unidades productivas en el año comercial 2007, estas fueron o debieron ser declaradas en el año tributario 2008. De esta forma, si el Servicios de Impuestos Internos hubiese fiscalizado estas operaciones en el año comercial 2014, los actos o negocios que generan el efecto tributario se habrían ejecutado en un período prescrito $y$, por ende, no revisables desde el punto de vista de la determinación de diferencias de impuesto o, más genéricamente, para corregir el resultado tributario declarado.

Por lo todo lo expuesto, de lege ferenda se considera que es necesario un cambio legislativo pues, de otro modo, las planificaciones tributarias ahora girarán en torno a la posibilidad de que la misma produzca efectos luego de seis años de fijados las características y elementos esenciales de los hechos, actos, negocios, o serie o conjunto de ellos. Con ello, las normas generales antielusión, pese a estar vigentes, resultarían inútiles para combatir el fenómeno elusivo.

\section{Conclusiones}

Del análisis efectuado, se puede concluir que la planificación tributaria es una actividad desarrollada por el contribuyente que persigue obtener un ahorro impositivo, con lo cual, por una parte, quedan comprendidos dentro de este concepto la economía de opción, el abuso de las formas jurídicas y la simulación, y por otra, es posible identificar y diferenciar dos conceptos que si bien están relacionados son diversos, a saber, la planificación tributaria y la economía de opción. El sistema tributario chileno admite los efectos tributarios emanados del ejercicio de la economía de opción, pues pese a que da lugar a un ahorro tributario, existe una concordancia entre la estructura jurídica utilizada y la realidad, sin contrariar la letra ni el espíritu de la ley; en cambio, el ordenamiento jurídico impositivo no acepta los efectos tributarios que derivan de actos, contratos o negocios abusivos, en los cuales se está ante un supuesto de elusión fiscal o simulados, en los cuales se está ante la evasión.

En efecto, lo propio de la elusión tributaria consiste en que se evite la realización del hecho gravado, por lo que no surge la obligación principal, esto es, la necesidad de enterar una suma en arcas fiscales, ni tampoco las obligaciones accesorias, que buscan caucionar el cumplimiento de la principal. El abuso de las formas jurídi- 
Particularidades de la prescripción en los supuestos de abuso de las formas jurídicas...

cas regulado en el artículo $4^{\circ}$ ter del Código Tributario, responde a la naturaleza jurídica de una norma general que busca evitar la elusión. Con todo, presenta ciertas particularidades importantes de mencionar: una de sus hipótesis supone la verificación del hecho gravado y su declaración corresponde a un tribunal de justicia y no a la Administración tributaria.

Por su parte, la simulación regulada en el artículo $4^{\circ}$ quáter del Código Tributario, pese a que ha sido calificada por el legislador como un caso de elusión, tiene más bien una naturaleza evasiva, pues el hecho gravado se verifica, pero hay ciertos aspectos que se disimulan, con lo cual, no se produce la satisfacción del crédito fiscal válidamente nacido. Esta figura también es declarada por un tribunal de justicia.

El hecho de que el legislador considere que tanto el abuso de las formas jurídicas como la simulación tienen naturaleza elusiva, genera problemas en sede sancionatoria, pero no en lo que se refiere al cobro del impuesto adeudado, debido a que desde el punto de la correcta determinación de la obligación tributaria al Fisco le interesará corregir los problemas que detecte en la declaración de impuestos; sin embargo, para efectos de castigo, la situación es diversa. En este sentido, no debieran ser sancionadas de igual forma conductas que suponen un rodeo del hecho gravado y un uso artificioso de formas jurídicas, y aquellas otras en las cuales hay una ocultación a la autoridad administrativa, pues ello vulnera el principio de proporcionalidad.

Expresamente, el legislador reconoce en el artículo $4^{\circ}$ bis del Código Tributario que los contribuyentes actúan de buena fe. A continuación, la disposición relaciona al abuso de las formas jurídicas y a la simulación con un actuar que no es de buena fe por parte del contribuyente, por lo que a contrario sensu, el obligado tributario se encontrará de mala fe en tales supuestos. Si se vincula esta circunstancia con los casos de prescripción extraordinaria, respecto de los impuestos sujetos a declaración, se puede afirmar que la declaración tributaria del contribuyente será maliciosamente falsa y, consecuentemente, su plazo se amplía a seis años, contados desde que expiró el plazo en el que debió efectuarse el pago.

Pese a que las medidas generales antielusivas del Código Tributario chileno están redactadas en términos objetivos, es posible afirmar que el elemento intencional está implícito en ellas y, por tanto, se puede sostener que la declaración es maliciosa. Ello resulta evidente en los casos de simulación, ya que el contribuyente oculta su situación tributaria a la Administración, pero también acontece respecto de la declaración del contribuyente en los supuestos de abuso de las formas jurídicas. A tal conclusión se arriba si se tiene presente, por una parte, que el contribuyente con su actuación también vulnera el ordenamiento jurídico para obtener un ahorro tributario, encontrando refugio de manera artificial en una norma de cobertura, e impidiendo la aplicación de la norma que imponía el gravamen. Refuerza esta afirmación, el 
hecho de que la prescripción de la acción para perseguir la aplicación de la sanción del artículo 100 bis del Código Tributario, aplicable en supuestos de elusión fiscal, presenta particularidades que la alejan de la regla general el cuanto al plazo de prescripción y el momento desde el cual se comienza a contar.

Analizadas las normas que regulan las cláusulas generales antielusión, se puede constatar que hay una opción del sistema tributario chileno, en el sentido de que lo que esencial para los efectos de la prescripción es considerar la época en que tuvo lugar la realización y conclusión del último de los actos jurídicos que integran la planificación tributaria objetada -pues a partir de ese momento potencialmente se puede obtener el ahorro tributario-, y no sigue el criterio según el cual lo relevante es que los efectos tributarios tengan lugar en un período que no se encuentre prescrito. El legislador, de esta manera, prescinde de la postura tradicional, ya que lo relevante será que el último de los actos, negocios o contratos abusivos o simulados se haya implementado en un período tributario susceptible de ser revisados por el ente fiscalizador.

Ahora bien, de lege ferenda, se estima necesario modificar esta regulación a fin de evitar que lo determinante para efectos de la prescripción de la acción de fiscalización sea el momento en que se realizó o concluyó el último de los actos que integran la planificación tributaria, pues con la normativa actualmente vigente, las planificaciones tributarias buscarán que sus efectos se produzcan una vez que haya concluido el plazo de prescripción de seis años. Con ello, las normas generales antielusión pese a estar vigentes, no serían un mecanismo útil para combatir el fenómeno elusivo.

\section{Referencias Bibliográficas}

Alessandri Rodríguez, A., Somarriva Undurraga, M., y Vodanovic Haklicka., A. (2009). Tratado de derecho civil: Partes preliminar y general (7a ed., Vol. 2). Santiago: Jurídica de Chile.

Alonso González, L. M. (2006). Planificación fiscal y economía de opción. Sentencias del Tribunal Superior de Justicia de Cataluña, Sala de lo Contencioso-Administrativo, Sección 4a, núms. 374 (JUR 2004, 155079), 554 (JUR 2004, 193496), 689 (JT 2004, 1119) y 896 (JUR 2004, 282567) de 2004. Jurisprudencia tributaria Aranzadi, (15)1, 3037-3060.

Alonso Madrigal, F. J. (2006). Fraude a la Ley tributaria, ilícito e infracción tributaria. ICADE (Madrid), (68), 159-195. Recuperado de https://bit.ly/2QYpL4y

Álvarez Barbeito, P. (2015). Posibilidad de declarar la existencia de fraude de ley en operaciones realizadas en ejercicios prescritos: análisis de las SSTS de 5 de febrero y 23 de marzo de 2015. Quincena Fiscal, (19), 179-187. 
Particularidades de la prescripción en los supuestos de abuso de las formas jurídicas...

Avilés Hernández, V. M. (2014). Legalidad tributaria y mecanismos antielusión (2a ed.). Santiago: Jurídica de Chile.

Báez Moreno, A. (2010). Algunas reflexiones sobre la prohibición de analogía en derecho tributario. En J. Arrieta Martínez de Pisón, M. A. Ángel Collado Yurrita, J. Zornoza Pérez (Dirs.), A. Báez Moreno y D. J. Jiménez-Valladolid de L'Hotellerie-Fallois (Coords.), Tratado sobre la ley general tributaria: homenaje a A'lvaro Rodríguez Bereijo (Vol. 1, pp. 453-471). Cizur Menor: Aranzadi Thomson Reuters.

Bas Soria, J. (2014). Declaración de fraude de ley de una operación realizada en un ejercicio prescrito (Análisis de la RTEAC de 11 de septiembre de 2014, RG 5852/2011). Estudios financieros. Revista de contabilidad y tributación. Comentarios, casos prácticos, (380), 145-154.

Blanche Reyes. C. (2014). La reforma tributaria 2014. Las nuevas medidas de control y el debido proceso. Revista del Abogado. Colegio de Abogados de Chile, 61, 9-11.

Boetsch Gillet, C. (2015). La buena fe contractual. Santiago: Ediciones UC.

Boetsch Gillet, C. (2016). La norma general anti elusión: análisis desde la perspectiva del derecho privado. Santiago: Ediciones UC.

Brzovic González, F. (2003). Evasión y elusión tributaria. Revista de derecho de la Universidad Finis Terrae, (7), 347-363.

Calvo Ortega, R. (2004). Ordenamiento tributario. En R. Calvo Ortega (Dir.) y J. M. Tejerizo López (Coord.), La nueva ley general tributaria (pp. 13-73). Madrid: Thomson Civitas.

Calvo Vérgez, J. (2007). Cláusula antiabuso versus fraude de ley ¿dos conceptos semejantes en la ley general tributaria?. Crónica tributaria, (123), 11-40.

Carrasquer Clari, M. L. (2002). El problema del fraude a la ley en el derecho tributario. Valencia: Tirant lo Blanch.

Cattaneo Escobar, I. y Burgos Arredondo, J. (2017). Elusión tributaria. Revista de estudios tributarios (En Línea), (17), 227-252. Recuperado de https://bit.ly/3m4ufVZ

Cipollina, S. (1992). La legge civile e la legge fiscale: Il problema dellelusione fiscale. Padova: CEDAM.

Circular $\mathrm{N}^{\circ}$ 41. Modificaciones introducidas por la Ley $\mathrm{N}^{\circ} 20.899$, que simplifica el sistema de tributación a la renta y perfecciona otras disposiciones legales, introducidas a los artículos 26 bis y 100 bis del Código Tributario y al procedimiento administrativo de calificación de actos o negocios como elusivos, incorporado en materia de medidas antielusivas por la Ley $N^{\circ}$ 20.780. Modifica Circular Nº 65, de 23 de julio de 2015. Sistema de Publicaciones Administrativas, Servicio de Impuestos Internos, Santiago, Chile, 11 de julio 2016. Recuperado de https://bit.ly/33vu0L5 
Circular $\mathrm{N}^{\circ} 42$. Vigencia y aplicación de las normas anti elusión establecidas en los artículos $4^{\circ}$ bis, $4^{\circ}$ ter, $4^{\circ}$ quáter, $4^{\circ}$ quinquies, 100 bis, 119 y 160 bis del Código Tributario. Sistema de Publicaciones Administrativas, Servicio de Impuestos Internos, Santiago, Chile, 11 de julio de 2016. Recuperado de https://bit.ly/2RtGrl1

Circular $\mathrm{N}^{\circ} 55$. Vigencia de las normas anti elusión establecidas en los artículos $4^{\circ}$ bis, $4^{\circ}$ ter, $4^{\circ}$ quáter, $4^{\circ}$ quinquies, 100 bis, 119 y 160 bis del Código Tributario. Complementa instrucciones contenidas en la Circular $N^{\circ} 55$ de 2014, de este Servicio. Sistema de Publicaciones Administrativas, Servicio de Impuestos Internos, Santiago, Chile, 24 de junio de 2015. Recuperado de https://bit.ly/3my5nGn

Circular $\mathrm{N}^{\circ}$ 65. Imparte instrucciones acerca de las normas incorporadas en el código tributario por la Ley $N^{\circ}$ 20.780, en materia de medidas anti elusión. Sistema de Publicaciones Administrativas, Servicio de Impuestos Internos, Santiago, Chile, 23 de julio 2015. Recuperado de https://bit.ly/3kpfSK9

Circular $N^{\circ}$ 73. Imparte instrucciones relativas a la aplicación de las normas de prescripción en el ejercicio de las acciones y facultades del servicio de impuestos internos. Servicio de Impuestos Internos, Santiago, Chile, 11 de octubre de 2001. Recuperado de https://bit.ly/3bZYM2i

Coca Cola Embonor S.A. con SII, RIT N GR-01-00003-2011 (Tribunal Tributario y Aduanero de la Región Arica y Parinacota 2 de abril de 2012). Recuperado de Recuperado de https://westlawchile.cl id: CL/JUR/1562/2012

Coca Cola Embonor S. A. con SII, Rol No 3-2012 (Corte de Apelaciones de Arica 6 de junio de 2012). Recuperado de https://vlex.cl id: 385091100

Coca Cola Embonor S.A. con Servicio de Impuestos Internos, Rol No 5118-2012 (Corte Suprema 23 de julio de 2013). Recuperado de https://westlawchile.cl id: CL/JUR/1604/2013

Código Civil. Diario Oficial de la República de Chile, Santiago, Chile, 30 de mayo de 2000. Recuperado de http://bcn.cl/1uqm8

Comercial Constructora Lomas Limitada con Servicio de Impuestos Internos VIII de Concepción, Rol N 100758-2016 (Corte Suprema 24 de enero de 2017). Recuperado de https://bit.ly/3ifvXS3

Comercial Key Limitada con Servicio de Impuestos Internos, Rol N 32114-2014 (Corte Suprema 14 de septiembre de 2015). Recuperado de https://westlawchile.cl id: CL/JUR/5508/2015

Decreto Ley $\mathrm{N}^{\circ}$ 824. Aprueba texto que indica de la Ley sobre impuesto a la renta. Diario Oficial de la República de Chile, Santiago, Chile, 31 de diciembre de 1974. Recuperado de http://bcn.cl/2f7ce 
Particularidades de la prescripción en los supuestos de abuso de las formas jurídicas...

Decreto Ley N 830. Código Tributario. Diario Oficial de la República de Chile, Santiago, Chile, 31 de diciembre de 1974. Recuperado de http://bcn.cl/1 uw3h

Doblevia Publicidad Limitada con Servicio de Impuestos Internos, Rol N 12915-2014 (Corte Suprema 26 de enero de 2015). Recuperado de https://westlawchile.cl id: $\mathrm{CL} / J U R / 320 / 2015$

Fernández Amor, J. A. y Masbernat Muñoz, P. (2011). El principio de capacidad económica en la jurisprudencia tributaria comparada de Chile y España. Revista de derecho (Valparaíso), (37), 567-593. doi: 10.4067/s0718-68512011000200015

Ferrara, F. (1960). La simulación de los negocios jurídicos (R. Atard y J. A. De la Puente, Trads.). Madrid: Revista de derecho privado.

Gárate González, C. (2015). La legítima razón. Cuadernos de extensión jurídica, (26), 179-220. Recuperado de https://bit.ly/3ISS8Q2

García Novoa, C. (2003). La posibilidad de imponer sanciones en los supuestos de fraude y abuso de la norma tributaria : el criticable contenido del art. 15.3 del Anteproyecto de Ley General Tributaria. Quincena fiscal, (8), 9-26.

García Novoa, C. (2004). La cláusula antielusiva en la nueva ley general tributaria. Madrid: Marcial Pons.

Hensel, A. (2005). Derecho tributario (A. Báez Moreno, M. L. González-Cuéllar Serrano y E. Ortiz Calle, Trads.). Barcelona: Marcial Pons.

Historia de la Ley $N^{\circ}$ 20.780. Reforma tributaria que modifica el sistema de tributación de la renta e introduce diversos ajustes en el sistema tributario. Biblioteca del Congreso Nacional, 29 de octubre de 2014. Recuperado de http://s.bcn.cl/1yhw5

Historia de la Ley $N^{\circ} 20.899$, Simplifica el Sistema de Tributación a la Renta y perfecciona otras disposiciones legales tributarias. Biblioteca del Congreso Nacional, 08 de febrero de 2016. Recuperado de http://s.bcn.cl/20k9k

Inmobiliaria Las Palmas de Maipú Dos S.A. con XV Dirección Regional Santiago Oriente del SIl, Rol N 14-9-0001790-2 (Tercer Tribunal Tributario y Aduanero de Santiago 10 de febrero de 2016). Recuperado de https://westlawchile.cl id: CL/JUR/4611/2016

Larenz, K. (1980). Metodología de la ciencia del derecho (M. Rodríguez Molinero, Trad.). Barcelona: Ariel.

Larraz López, J. (1952). Metodología aplicativa del derecho tributario. Madrid: Revista de derecho privado.

Ley 230/1963, de 28 de diciembre, General Tributaria. Boletín Oficial del Estado, Madrid, España, 31 de diciembre de 1963. Recuperado de https://bit.ly/2H5vjJ2 
Ley 58/2003, de 17 de diciembre, General Tributaria. Boletín Oficial del Estado, Madrid, España, 17 de diciembre 2003. Recuperado de https://bit.ly/2RHmGqh

Ley $\mathrm{N}^{\circ}$ 20.780. Reforma tributaria que modifica el sistema de tributación de la renta e introduce diversos ajustes en el sistema tributario. Diario Oficial de la República de Chile, Santiago, Chile, 29 de septiembre de 2014. Recuperado de http://bcn.cl/2kzeb

Ley $\mathrm{N}^{\circ}$ 20.899. Simplifica el sistema de tributación a la renta y perfecciona otras disposiciones legales tributarias. Diario Oficial de la República de Chile, Santiago, Chile, 08 de febrero de 2016. Recuperado de http://bcn.cl/2k1ds

López López, H. y Báez Moreno, A. (2004). Nuevas perspectivas generales sobre la elusión fiscal y sus consecuencias en la derivación de responsabilidades penales. (Comentario a la Sentencia del TS de 30 de abril de 2003, rec. núm. 3435/2001). Estudios financieros. Revista de contabilidad y tributación. Comentarios, casos prácticos, (251), 119-137.

Marín Benítez, G. (2013). ¿Es lícita la planificación fiscal?: sobre los defectos de neutralidad y consistencia del ordenamiento tributario. Valladolid: Thomson Reuters-Lex Nova.

Massone Parodi, P. (2016). Principios de derecho tributario (4a ed., Vol. 1). Santiago: Thomson Reuters.

Matus Fuentes, M. (2017). La elusión tributaria y su sanción en la Ley N 20.780: Hacia un concepto de negocio jurídico elusivo. lus et praxis, 23(1), 67-90. doi: $10.4067 /$ s0718-00122017000100003

Montecinos Araya, J. (2000). De la elusión y la evasión tributaria. Revista de derecho (Concepción. En línea), 68(207), 151-162. Recuperado de https://bit.ly/35aN9UO

Osorio Morales, H. y González Orrico, J. (2016). De la elusión. Aproximación teórica. En H. Osorio Morales, J. González Orrico, C. Vildósola Godoy, y V. Vidal Chavarría (Autores), Un acercamiento al abuso de las formas jurídicas (pp. 15-67). Santiago: Librotecnia.

Pablo Andrés Gajardo Muñoz con Servicio de Impuestos Internos, Rol N 25915-2014 (Corte Suprema 27 de julio de 2015). Recuperado de https://westlawchile.cl id: CL/JUR/4207/2015

Palao Taboada, C. (2009a). La norma anti-elusión del proyecto de nueva ley general tributaria. En su: La aplicación de las normas tributarias y la elusión fiscal (pp. 147-174). Valladolid: Lex Nova.

Palao Taboada, C. (2009b). Prólogo. En A. Báez Moreno (Autor), Los negocios fiduciarios en la imposición sobre la renta (pp. 17-25). Cizur Menor: Aranzadi.

Palao Taboada, C. (2014). Doctrina de los actos propios, comprobación de ejercicios anteriores y fraude de ley. (Comentario a la STS de 4 de noviembre de 2013, rec. núm. 
Particularidades de la prescripción en los supuestos de abuso de las formas jurídicas...

28/2010). Estudios financieros. Revista de contabilidad y tributación. Comentarios, casos prácticos, (376), 5-48.

Por una reforma tributaria para un Chile más inclusivo. Protocolo de acuerdo. Santiago de Chile, 08 de julio de 2014. Recuperado de https://bit.ly/3iQZh1z

Real Academia Española. (2014). Diccionario de la lengua española (23a ed.). Recuperado de https://dle.rae.es

Recurso No 682/2014 (Tribunal Supremo 23 de marzo de 2015). Recuperado de https://vlex.cl id: 564647154

Recurso $N^{\circ}$ 1285/2012 (Tribunal Supremo 4 de julio de 2014). Recuperado de https://vlex.cl id: 521679330

Recurso $N^{\circ} 2218 / 2015$ (Tribunal Supremo 22 de junio de 2016). Recuperado de https://vlex.cl id: 644351849

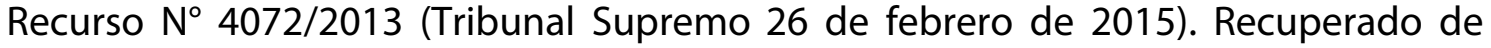
https://vlex.cl id: 563117218

Recurso No 4075/2013 (Tribunal Supremo 5 de febrero de 2015). Recuperado de https://vlex.cl id: 563116714

Resolución Nº5852/2011 (Tribunal Económico Administrativo Central. 11 de septiembre de 2014). Recuperado de https://bit.ly/3c4fJZI

Resolución Exenta $\mathrm{N}^{\circ}$ 68. Crea Comité Anti elusión y fija sus atribuciones y funciones. Servicio de Impuestos Internos, Santiago, Chile, 11 de julio 2016. Recuperado de https://bit.ly/35lolDZ

Rozas Valdés, J. A. y Anderson, M. (2007). ¿Simulación civil o recalificación tributaria?. Jurisprudencia tributaria (Ed. quincenal), (18), 9-28.

Ruiz Almendral, V. y Zornoza Pérez. J. (2005). Interpretación, calificación, integración y medidas antielusión en la Ley 58/2003, de 17 de diciembre, General Tributaria. En J. Zornoza Pérez (Dir.) La reforma de la Ley General Tributaria (pp. 11-84). Madrid: Consejo General del Poder Judicial. Centro de Documentación.

Sainz de Bujanda, F. (1966). Fundamento del hecho imponible. En su: Hacienda y derecho (Vol. 4, pp. 421-564). Madrid: Instituto de Estudios Políticos.

Salassa Boix, R. (2016). Tributos ambientales: La aplicación coordinada de los principios quien contamina paga y de capacidad contributiva. Revista chilena de derecho, 43(3), 1005-1030. doi: 10.4067/s0718-34372016000300010

Servicio de Impuestos Internos. (2019). Catálogo de Esquemas Tributarios 2018. Recuperado de https://bit.ly/337l52b 
Sociedad Comercial y de Inversiones Ltda. con Servicio de Impuestos Internos, Rol $\mathrm{N}^{\circ}$ 6979-2015 (Corte Suprema 22 de junio de 2015). Recuperado de https://westlawchile.cl id: CL/JUR/3498/2015

Sociedad Inmobiliaria Bahía S. A. contra S.I.I., Rol N 4.038-2001 (Corte Suprema 28 de enero de 2003). Recuperado de https://bit.ly/2DLjxIR

Tiedemann, K. (2010) Manual de Derecho penal económico. Parte general y especial. Valencia: Tirant lo Blanch.

Ugalde Prieto, R. (2018a). La elusión tributaria: el abuso de las formas jurídicas y la simulación. Santiago: Jurídica de Chile.

Ugalde Prieto, R. (2018b). La elusión tributaria: la declaración judicial de la elusión. Santiago: Jurídica de Chile.

Ugalde Prieto, R. y García Escobar, J. (2010). Elusión, planificación y evasión tributaria (4a ed.). Santiago: Legal Publishing.

Vergara Hernández, S. (2006). Planificación tributaria \& tributación: Teoría general de la PT: Estudios de casos de PT: Análisis de jurisprudencia. Santiago: Tributaria Nova Lex.

Vergara Quezada, G. (2015). ¿Se han resuelto en Chile casos de lo que doctrinariamente podemos considerar elusión?. Revista de estudios tributarios (En línea), (14), 199-238. Recuperado de https://bit.ly/2R6iH6j

Vergara Quezada, G. (2016). Norma antielusiva general. Sobre los fines en nuestras leyes tributarias. Santiago: Libromar.

Walker Mena, R. (2017). Hacia una interpretación jurídica de la economía de opción y el abuso en la norma general antielusión del Código Tributario. Revista de estudios tributarios (En línea), (18), 133-166. Recuperado de https://bit.ly/3idAB2T

Yáñez Villanueva, F. (2014). Análisis de la nueva cláusula general antielusiva. Revista de estudios tributarios (En línea), (11), 233-250. Recuperado de https://bit.ly/3bDn41S

\section{Para citar este artículo bajo Norma APA 6a ed.}

Navarro Schiappacasse, M. P. (2020). Particularidades de la prescripción en los supuestos de abuso de las formas jurídicas y simulación en el Código Tributario chileno. Revista de derecho (Coquimbo. En línea), 27, e4467, https://doi.org/10.22199/issn.0718-9753-2020-0014 